\title{
Somatostatin reduces gastric mucosal blood flow in normal subjects but not in patients with cirrhosis of the liver
}

\author{
A SONNENBERG AND C WEST \\ From the Medical Department D, University of Düsseldorf, Federal Republic of Germany
}

SUMMARY The effects of 1 and $4 \mu \mathrm{g} / \mathrm{kg} / \mathrm{h}$ somatostatin on pentagastrin-stimulated gastric mucosal blood flow and acid secretion were investigated in 12 normal subjects and in 12 patients with cirrhosis of the liver. Each dose of somatostatin was given intravenously to six normal subjects and to six patients. Gastric mucosal blood flow was measured by the neutral red clearance of the stomach. Pentagastrin at a dose of $0.67 \mu \mathrm{g} / \mathrm{kg} / \mathrm{h}$ stimulated acid secretion less in patients with cirrhosis of the liver than in normal subjects. In normal subjects $1 \mu \mathrm{g} / \mathrm{kg} / \mathrm{h}$ somatostatin induced a parallel decline of gastric mucosal blood flow and gastric secretion; with $4 \mu \mathrm{g} / \mathrm{kg} / \mathrm{h}$ somatostatin mucosal blood flow was inhibited more than gastric secretion. In patients with cirrhosis of the liver gastric mucosal blood flow remained unaffected by both doses of somatostatin, while acid secretion was slightly decreased. It is concluded that somatostatin can affect gastric mucosal blood flow independently of acid secretion. Somatostatin may be ineffective in the treatment of gastric haemorrhage in patients with cirrhosis of the liver.

In a controlled clinical trial somatostatin at a dose of $250 \mu \mathrm{g} / \mathrm{kg} / \mathrm{h}$ has been shown to stop the acute haemorrhage from peptic lesions. ${ }^{1}$ In normal subjects 25()$\mu \mathrm{g} / \mathrm{h}$ somatostatin lowered splanchnic blood flow; in patients with cirrhosis of the liver wedged hepatic venous pressure and splanchnic blood flow remained unaffected by the same dose of somatostatin. ${ }^{2}$ Nevertheless, somatostatin has been claimed to be effective in the treatment of bleeding oesophageal varices. ${ }^{3}$ In order to elucidate further the effects of somatostatin on the blood supply to the mucosa in the gastrointestinal tract, mucosal blood flow during somatostatin infusion was measured by the neutral red clearance of the stomach in 12 normal subjects and in 12 patients with cirrhosis of the liver.

\section{Methods}

SUBJECTS

Twelve patients with cirrhosis of the liver (two) women and 10 men) participated in the study: mean age was $52 \pm 15$ years $(\bar{x} \pm S D)$. All patients had a history of excessive alcohol consumption.

Received for publication 17 Mat! 19xz
Micronodular cirrhosis of the liver had been diagnosed by laparoscopy; upper gastrointestinal endoscopy revealed oesophageal varices in all patients. Eight of them had a past history of bleeding from oesophageal varices, nine patients had ascites. The experiments were performed before any therapy with diuretics had been started.

Twelve volunteers served as age- and sex-matched controls, mean age being $48 \pm 12$ years. The control group was made up of subjects who had been admitted to the hospital with suspected gastrointestinal disease, but in whom clinical investigation did not reveal disease. The clinical investigation included laboratory analyses of serum bilirubin, alkaline phosphatase, glutamic pyruvic transaminase, glutamic oxalacetic transaminase. albumin, electrophoresis, and prothrombin time.

All subjects gave written informed consent. The study had been approved by the local ethical committee.

EXPERIMENTAI, PROCEDURE

Gastric mucosal blood flow was estimated by the neutral red clearance of the stomach. ${ }^{+-6}$ The experiment started at 8 am after an overnight fast. A double lumen nasogastric tube was positioned under fluoroscopic control with its tip lying in the antrum. 
The gastric contents were aspirated constantly with a mechanical pump and pooled in 15 minute fractions. Blood samples were drawn from a peripheral arm vein every 15 minutes during the first hour and every 30 minutes thereafter. The experiment lasted four hours. It started with a bolus injection of $250 \mu \mathrm{g} / \mathrm{kg}$ neutral red (British Drug House). Throughout the experiment $250 \mu \mathrm{g} / \mathrm{kg} / \mathrm{h}$ neutral red and $0.67 \mu \mathrm{g} / \mathrm{kg} / \mathrm{h}$ pentagastrin (Merck) were infused intravenously. From the third hour onwards somatostatin (Serono) at a dose of 1 $\mu \mathrm{g} / \mathrm{kg} / \mathrm{h}$ or $4 \mu \mathrm{g} / \mathrm{kg} / \mathrm{h}$ was infused intravenously. Each dose of somatostatin was tested in six patients with cirrhosis of the liver and in six controls. Of the nine patients with ascites, five were given $1 \mu \mathrm{g} / \mathrm{kg} / \mathrm{h}$ and four patients $4 \mu \mathrm{g} / \mathrm{kg} / \mathrm{h}$ somatostatin. Neutral red like any other weak base accumulates in the gastric lumen only in the presence of acid. ${ }^{7}$ Therefore, during the inhibition of gastric secretion by $4 \mu \mathrm{g} / \mathrm{kg} / \mathrm{h}$ somatostatin the stomach was perfused with $15 \mathrm{ml} / 15 \mathrm{~min}$ of $10 \mathrm{mmolar}$ hydrochloric acid containing $1 \%$ polyethylene glycol. ${ }^{8}$ The perfusion was performed with a precision pump (BraunMelsungen). In order to assess the effect of the acidic perfusion on neutral red clearance, the experiments with 1 and $4 \mu \mathrm{g} / \mathrm{kg} / \mathrm{h}$ somatostatin were conducted twice in two patients with cirrhosis of the liver, once with and once without, acidic perfusion. In both patients the $\mathrm{R}$-value and the neutral red clearance at any time of the double experiments differed by less than $20 \%$.

LABORATORY ANALYSES

Neutral red was extracted from $10 \mathrm{ml}$ of alkalinised blood samples and $3 \mathrm{ml}$ of alkalinised gastric juice with diethylether according to the method of Knight et al. ${ }^{56}$ and transferred to an acidic aqueous phase. The concentration of neutral red was measured by photometry at a wavelength of $540 \mathrm{~nm}$. Acid output was determined by titration of $0.5 \mathrm{ml}$ gastric contents with $0.1 \mathrm{n} \mathrm{NaOH}$ to a pH of 7.0 on an automatic titrator. Polyethylene glycol concentration was determined by the turbidimetric method of Malawer et al. ${ }^{9}$

\section{Calculations}

The gastric clearance of neutral red (NRC) is

$$
\mathrm{NRC}=\frac{\mathrm{NR}_{\mathrm{g}}}{\mathrm{NR}_{\mathrm{b}}} \times \mathrm{V}=\mathrm{R} \times \mathrm{V}
$$

where $N_{\mathrm{g}}$ and $\mathrm{NR}_{\mathrm{h}}$ are the concentration of neutral red in the gastric secretion and in the blood. and $\mathrm{V}$ is the gastric volume secreted per time unit. The ratio of neutral red clearance over volume secretion was named R-value. ${ }^{7}$ During gastric perfusion with $10 \mathrm{mmolar} \mathrm{HCl}$ the total intragastric volume $\left(\mathrm{V}_{\text {stomach }}\right)$ was calculated from the dilution of the polyethylene glycol in the stomach:

$$
\mathrm{V}_{\text {stomach }}=\mathrm{V}_{\text {perfusate }} \times \frac{\mathrm{PEG}_{\text {perfusate }}}{\mathrm{PEG}_{\text {aspirate }}}
$$

$\mathrm{V}_{\text {perfusate }}$ is the volume perfused per 15 minutes $(=15$ $\mathrm{ml}), \quad \mathrm{PEG}_{\text {perfusate }}$ and $\mathrm{PEG}_{\text {aspirate }}$ are the concentration of polyethylene glycol in the perfused and aspirated volume. The gastric volume secreted per 15 minutes is

$$
\mathrm{V}=\mathrm{V}_{\text {stomach }}-\mathrm{V}_{\text {perfusate }}
$$

The concentration of neutral red in the gastric secretion $\left(\mathrm{NR}_{\mathrm{g}}\right)$ is

$$
\mathrm{NR}_{\mathrm{g}}=\mathrm{NR}_{\text {aspirate }} \times \frac{\mathrm{V}_{\text {stomach }}}{\mathrm{V}}
$$

where $\mathrm{NR}_{\text {aspirate }}$ is the concentration of neutral red in the aspirated volume. In the absence of gastric perfusion $\mathrm{V}=\mathrm{V}_{\text {stomach }}$ and $\mathrm{NR}_{\mathrm{g}}=\mathrm{NR}_{\text {aspirate }}$.

STATISTICAL ANALYSES

For statistical comparison the acid output and the average values of the neutral red clearance and the $\mathrm{R}$-values of the second and fourth hour were used. ${ }^{10}$ The differences (1) between controls and liver cirrhosis and (2) between the pentagastrin and the pentagastrin + somatostatin infusion were evaluated by the unpaired and paired Student's $t$-test, respectively.

\section{Results}

Neutral red appeared in the gastric juice three to six minutes after the bolus injection. After a brief rise, the concentration of neutral red in the gastric aspirates steadily declined during the first 30-45 minutes, while it remained virtually constant in the blood from the beginning onwards. Accordingly, the $R$-value and the neutral red clearance showed an initial fall before a steady state under pentagastrin was reached (Fig. 1). The initial fall of the R-value and the neutral red clearance was more pronounced in the control group than in the patients with cirrhosis of the liver (Fig. 2). Pentagastrin infusion induced an initial rise of acid secretion in the first hour; in the second hour acid secretion remained constant or showed a slight decrease. The 12 patients with cirrhosis had lower acid secretion, neutral red clearance, and R-values than the 12 controls (Table).

In the control group somatostatin at a dose of 1 $\mu \mathrm{g} / \mathrm{kg} / \mathrm{h}$ induced a sharp fall of the pentagastrin stimulated acid secretion. As the neutral red clearance fell parallel to the volume and acid secretion, the $\mathrm{R}$-value remained practically unchanged. The 

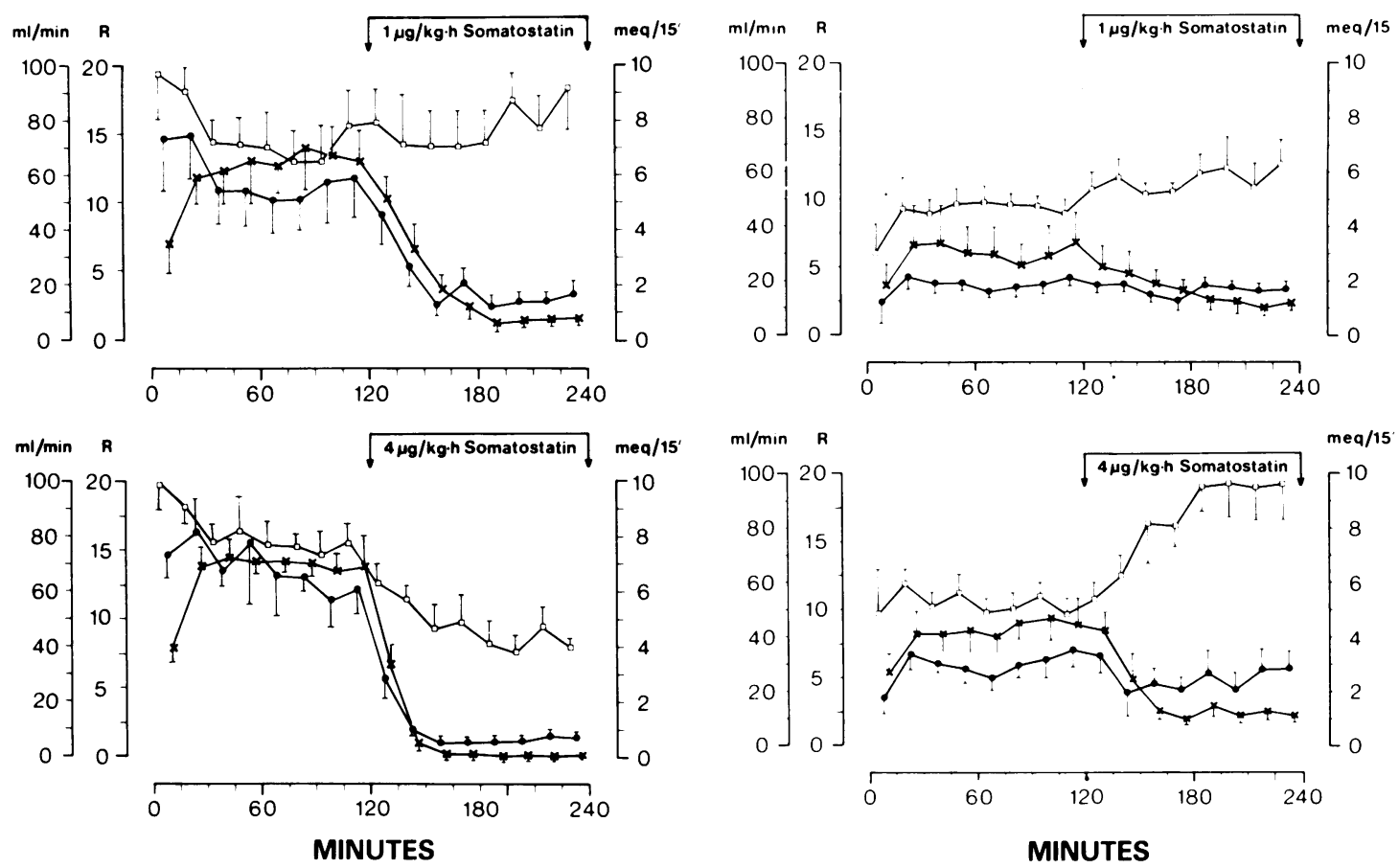

Fig. 1 Effect of intravenous somatostatin on gastric acid secretion $(\times-\times)$, neutral red clearance $(\bullet-\bullet)$, and $R$-1alue ( $\square \longrightarrow \sqsupset)$ in normal subjects. Gastric secretion w'as stimulated by intravenous infusion of (0.67 $\mu \mathrm{g} / \mathrm{kg} / \mathrm{h}$ pentagastrin. Each point is mean $\pm S E M$ of six subjects.

effect of somatostatin was more pronounced at a dose of $4 \mu \mathrm{g} / \mathrm{kg} / \mathrm{h}$. Less than $1 \mathrm{meq} / \mathrm{h}$ hydrochloric acid was secreted. Neutral red clearance were inhibited to a larger extent than volume secretion, and, hence, the R-values dropped significantly below those observed under steady state conditions

Fig. 2 Effect of intravenous somatostatin on gastric acid secretion $(\times-\times)$, neutral red clearance $(\bullet-\bullet)$, and $R$-value $(\square-\square)$ in patients with cirrhosis of the liver. Gastric secretion was stimulated by intravenous infusion of (). $67 \mu \mathrm{g} / \mathrm{kg} / \mathrm{h}$ pentagastrin. Each point is mean \pm SEM of six subjects.

when pentagastrin was given alone (Fig. 1).

In the patients with liver cirrhosis $1 \mu \mathrm{g} / \mathrm{kg} / \mathrm{h}$ somatostatin inhibited pentagastrin-stimulated acid secretion less than in the control group (Table). In contrast with controls, neutral red clearance remained unaffected. The $R$-value slightly

Table Acid output, neutral red clearance, and $R$-value of second hour with pentagastrin given alone and of fourth hour with pentagastrin given together with 1 or $4 \mu \mathrm{g} / \mathrm{kg} / \mathrm{h}$ somatostatin

\begin{tabular}{|c|c|c|c|c|}
\hline & Pentagastrin & $\begin{array}{l}\text { Pentagastrin }+ \\
l \mu g \text { somatostatin }\end{array}$ & Pentagastrin & $\begin{array}{l}\text { Pentagastrin }+ \\
4 \mu g \text { somatostatin }\end{array}$ \\
\hline \multicolumn{5}{|l|}{ Normal subjects } \\
\hline Acid output (meq/h) & $26 \cdot 9 \pm 13 \cdot 1$ & $3 \cdot 2 \pm 1 \cdot 8^{*}$ & $27 \cdot 8 \pm 4 \cdot 9$ & $0 \cdot 3 \pm 0 \cdot 4^{*}$ \\
\hline Clearance $(\mathrm{ml} / \mathrm{min})$ & $55 \pm 32$ & $15 \pm 7^{*}$ & $63 \pm 18$ & $6 \pm 3^{*}$ \\
\hline R-value & $14 \pm 6$ & $16 \pm 5$ & $15 \pm 3$ & $8 \pm 3^{*}$ \\
\hline \multicolumn{5}{|l|}{ Liver cirrhosis } \\
\hline Acid output (meq/h) & $12 \cdot 1 \pm 9 \cdot 6 \div$ & $4 \cdot 9 \pm 2 \cdot 5^{*}$ & $18 \cdot 4 \pm 6 \cdot 0 \div$ & $5 \cdot 3 \pm 2 \cdot 4^{*} \dagger$ \\
\hline Clearance $(\mathrm{ml} / \mathrm{min})$ & $18 \pm 8 \div$ & $15 \pm 5$ & $30 \pm 11 \div$ & $26 \pm 15+$ \\
\hline R-value & $9 \pm 2$ & $12 \pm 5$ & $10 \pm 2 \div$ & $19 \pm 5^{*}+$ \\
\hline
\end{tabular}

Each value represents mean \pm SD of six subjects.

${ }^{*} \mathrm{p}<0.05$ for the comparison: pentagastrin i's pentagastrin + somatostatin by paired Student 's $t$ tests.

$\div \mathrm{p}<0.05$ for the comparison: liver cirrhosis i's normal subjects by unpaired Student's $t$ tests 
increased. The different action of somatostatin in liver cirrhosis than in healthy controls became even more apparent with $4 \mu \mathrm{g} / \mathrm{kg} / \mathrm{h}$ : despite the lower starting level under pentagastrin, acid secretion with somatostatin was significantly higher than in controls.

The neutral red clearance again remained unaffected, and the R-value significantly increased (Fig. 2).

A significant linear correlation existed between gastric acid secretion and neutral red clearance. The positive intercepts of the regression lines with the $y$-axis representing neutral red clearance were similar in both groups of subjects (Fig. 3).

In the control group and in the patients' group both concentrations of somatostatin left systolic and diastolic blood pressure and pulse rate unchanged compared with the pentagastrin period.

\section{Discussion}

In normal subjects low dose somatostatin induced a parallel decline of gastric secretion and mucosal blood flow; at a high dose, blood flow was inhibited more than gastric secretion. In patients with cirrhosis of the liver gastric mucosal blood flow remained unaffected by both doses of somatostatin.

For the measurement of gastric mucosal blood flow the neutral red clearance of the stomach was used. After the bolus injection neutral red accumulates inside the parietal cells and is consecutively washed out of the cells by the acid secretion. ${ }^{112}$ The initial fall of the neutral red clearance and the R-value thus does not correspond with real changes of blood flow. Only the values of the second hour represent steady state of mucosal blood flow under pentagastrin. Gastric neutral red and aminopyrine clearance appear to reflect both gastric mucosal blood flow and parietal cell function. They should only be used as relative measures of gastric mucosal blood flow. These drawbacks of clearance markers in general must be considered when the results of the present study are to be interpreted. ${ }^{2}$

Cirrhotic patients are less responsive to pentagastrin stimulated acid secretion than normal subjects. Because of the decreased capacity for acid secretion in these patients less neutral red is trapped in their mucosa after the bolus injection (Fig. 2). It could mean that their parietal cells do respond less to stimulation, or it may reflect a restraint in blood flow. Unlike the healthy subjects, the cirrhotic patients exhibit a marked decrease of acid output only with a high dose of somatostatin, the decrease still being far less than in the healthy subjects. The reason for this diminished response is unknown. It has been shown that somatostatin is degraded by the liver. ${ }^{13}$ Degradation may be impaired, thus leading to abnormally high levels of somatostatin in cirrhotic patients. With high pre-existing plasma levels of somatostatin. low dose infusion of somatostatin might be ineffective. This, however, is speculative, since no data on the pharmacokinetics of somatostatin in liver cirrhosis exist.

After an intravenous infusion of somatostatin a $30 \%$ reduction in splanchnic blood flow occurs in normal subjects. ${ }^{14}$ is Our study shows that in normal subjects somatostatin inhibits mucosal blood flow in a dose dependent way. Thus, the reduction of splanchnic blood flow also involves those blood vessels which may become responsible for gastrointestinal haemorrhage. In patients with cirrhosis of the liver the mucosal blood flow remained unaffected by any dose of somatostatin. During pentagastrin infusion of patients with cirrhosis of the liver, gastric neutral red clearance was considerably
Fig. 3 Linear regression between acid secretion and neutral red clearance during infusion of pentagastrin given alone (left) or together with somatostatin (right). $\bullet$ Healthy subjects, $\square$ patients with cirrhosis of the liver, o healthy subject disregarded in the linear regression. For all $r, p<0.05$.
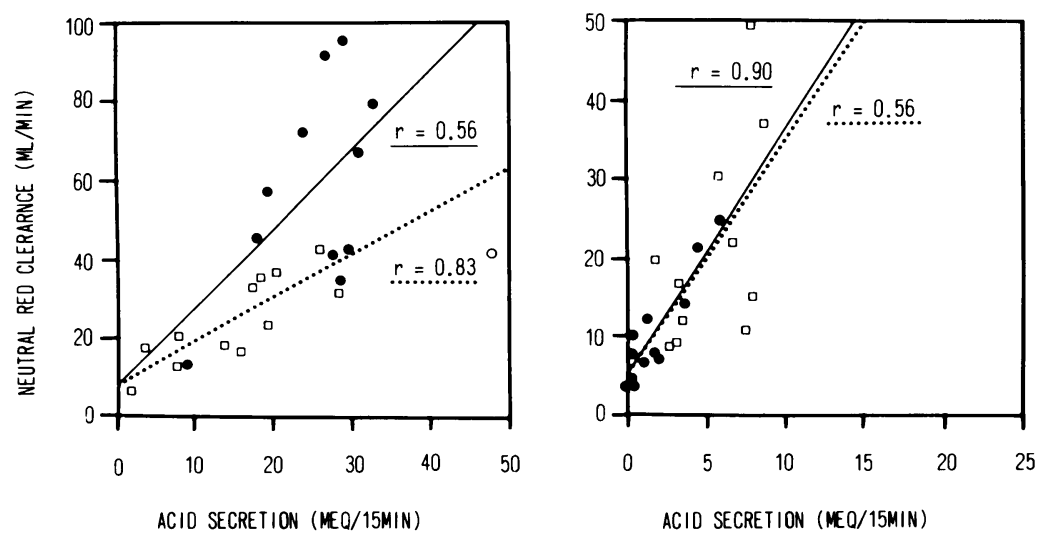
less than in normal subjects. Somatostatin may be ineffective in these patients because it is difficult to suppress further an already decreased acid output. During somatostatin inhibition, however, neutral red clearance in normal subjects fell below the values observed in the cirrhotic patients. To shed more light on this problem it might be helpful to study the group of patients with a low acid output for example, patients with gastric ulcer or pernicious anaemia.

After an intravenous infusion of $7.5 \mu \mathrm{g} / \mathrm{min}$ somatostatin to patients with cirrhosis of the liver, Bosch and coworkers have observed a $17.5 \%$ reduction in splanchnic blood flow measured by the indocyanine green method. ${ }^{16}$ Little indocyanine green is extracted from the blood by the cirrhotic liver, however, and this change in blood flow may be below the range which can be detected by this method. ${ }^{17}$ Sonnenberg et al using a smaller dose of $250 \mu \mathrm{g} / \mathrm{h}$ somatostatin have found a $33 \%$ decline of splanchnic blood flow in normal subjects, but no effect of somatostatin in patients with cirrhosis of the liver. ${ }^{2}$ These findings are corroborated by our results.

Total stimulated blood flow is a combination of resting flow $\left(\mathrm{NRC}_{\mathrm{r}}\right)$ and stimulated flow $\left(\mathrm{NRC}_{\mathrm{s}}\right)$ : $\mathrm{NRC}=\mathrm{NRC}_{\mathrm{r}}+\mathrm{NRC}_{\mathrm{s}}=\mathrm{R} \cdot \mathrm{V}$. The greater the stimulated flow the less the contribution of resting flow to total flow, and, conversely; the less the stimulation the greater the contribution of resting to total flow. $\mathrm{R}$ then reflects the changing contributions of these two factors to total flow. In the absence of volume secretion there is still resting blood flow. The regression of blood flow vs volume or acid secretion has a positive intercept corresponding with $\mathrm{NRC}_{\mathrm{r}}$ (Fig. 3). In the absence of acid secretion there is still trapping of neutral red by the induced acid environment after the infusion of extrinsic acid. It could, therefore, be concluded that, providing neutral red clearance reflects changes in blood flow, then the unchanged $\mathrm{R}$-value after the infusion of 1 $\mu \mathrm{g} / \mathrm{kg} / \mathrm{h}$ somatostatin to healthy subjects is compatible with the blood flow restraining acid secretion. Somatostatin at a dose of $2.5 \mu \mathrm{g} / \mathrm{kg} / \mathrm{h}$ caused a marked decrease of canine mucosal blood flow measured by the ${ }^{14} \mathrm{C}$-aminopyrine clearance. ${ }^{18}$ As at this dose the $\mathrm{R}$-value remained constant, the authors concluded that the reduction in mucosal blood flow was secondary to an inhibition of gastric secretion - a conclusion different from ours.

Our experiments with $4 \mu \mathrm{g} / \mathrm{kg} / \mathrm{h}$ somatostatin showed a decrease of the $\mathrm{R}$-value in healthy subjects and an increase in liver cirrhosis, though in both groups somatostatin reduced gastric secretion. Thus, somatostatin, at least at high doses, can act independently, on both, gastric secretion and mucosal blood flow. The decrease of the R-value in healthy subjects suggests that somatostatin inhibits gastric mucosal blood flow more than gastric secretion. In cirrhotic patients the R-value increases during the somatostatin inhibition of the gastric mucosa because of a relative sparing of the mucosal blood flow. The splanchnic system seems to be particularly sensitive to somatostatin, while other vessel systems do not respond to it. ${ }^{1920}$ The sensitivity of the splanchnic system is disturbed by liver cirrhosis for unknown reasons. This has so far been demonstrated for the total splanchnic system and in this study for the gastric mucosal blood flow. Somatostatin may be ineffective in the treatment of gastric haemorrhage in patients with cirrhosis of the liver.

This study was supported by a grant from the Minister für Wissenschaft und Forschung des Landes Nordrhein-Westfalen.

\section{References}

1 Kayasseh L, Gyr K, Keller U, Stalder GA, Wall M. Somatostatin and cimetidine in peptic ulcer haemorrhage. A randomized controlled trial. Lancet 1980; 1: 844-6.

2 Sonnenberg GE, Keller U, Perruchoud A, Burckhardt $\mathrm{D}$, Gyr K. Effect of somatostatin on splanchnic hemodynamics in patients with cirrhosis of the liver and in normal subjects. Gastroenterology 1981; 80: 526-32.

3 Thulin L, Tydén G, Samnegård H, Muhrbeck O, Efendić $\mathrm{S}$. Treatment of bleeding oesophageal varices with somatostatin. Acta Chir Scand 1979; 145: 395-8.

4 Aures D, Guth PH, Grossman MI. The use of neutral red to measure gastric mucosal blood flow in man. Gastroenterology 1975; 68: A-200/1057.

5 Knight SE, McIsaac RL, Rennie CD. The effect of histamine and histamine antagonists on gastric acid secretion and mucosal blood flow in man. Br J Surg 1980; 67: 266-8.

6 Knight SE, McIsaac RL, Rennie CD, Flannery MC, Fielding LP. Studies of gastric mucosal blood flow: neutral red clearance and dose-response curve analysis. In: Fielding LP, ed. Gastro-intestinal mucosal blood flow. Edinburgh: Churchill Livingstone, 1980: 105-24.

7 Jacobson ED, Linford RH, Grossman MI. Gastric secretion in relation to mucosal blood flow studied by a clearance technique. J Clin Invest 1966; 45: 1-13.

8 Cowley DJ, Code CF. Effects of secretory inhibitors on mucosal blood flow in nonsecreting stomach of conscious dogs. Am J Physiol 1970; 218: 27(1-4. 
9 Malawer SJ, Powell DW. An improved turbidimetric analysis of polyethylene glycol utilizing an emulsifier. Gastroenterology 1967; 53: 250-6.

10 Elashoff JD. Down with multiple t-tests! Gastroenterology 1981; 80: 615-20.

11 Sonnenberg A, Blum AL. Limitations to measurement of gastric mucosal blood flow by ${ }^{14} \mathrm{C}$-aminopyrine clearance. In: Fielding LP, ed. Gastro-intestinal mucosal blood flow. Edinburgh: Churchill Livingstone, 1980: 43-58.

12 Müller-Lissner SA, Sonnenberg A, Blum AL. Does gastric aminopyrine clearance reflect gastric mucosal blood flow or parietal cell function? Gut 1981; 22: 997-1002.

13 Sacks H, Terry LC. Clearance of immunoreactive somatostatin by perfused rat liver. J Clin Invest 1981; 67: 419-29.

14 Wahren J, Felig P. Influence of somatostatin on carbohydrate disposal and absorption in diabetes mellitus. Lancet 1976; 2: 1213-6.

15 Keller U, Sonnenberg GE, Kayasseh L, Gyr K,
Perruchoud A. Dosisabhängigkeit der Wirkung von Somatostatin auf die splanchnische Durchblutung beim Menschen. Schweiz Med Wochenschr 1979; 109: 595-6.

16 Bosch J, Kravetz D, Rhodes J. Effects of somatostatin on hepatic and systemic hemodynamics in patients with cirrhosis of the liver: comparison with vasopressin. Gastroenterology 1981; 80: 518-25.

17 Paumgartner $\mathrm{G}$. The handling of indocyanine green by the liver. Schweiz Med Wochenschr 1975; 105: Special supplementum.

18 Konturek SJ, Tasler J, Cieszkowski M, Coy D, Schally A. Effect of growth hormone release-inhibiting hormone on gastric secretion, mucosal blood flow, and serum gastrin. Gastroenterology 1976; 70: 737-41.

19 Rosenthal J, Escobar-Jimenez F, Raptis S. Prevention by somatostatin of rise in blood pressure and plasma renin mediated by beta-receptor stimulation. Clin Endocrinol 1977; 6: 455-62.

20 Jaspan J, Polonsky K, Lewis M, Moossa AR. Reduction in portal vein blood flow by somatostatin. Diabetes 1979; 28: 888-92. 